\title{
Ceratite infecciosa em crianças: estudo microbiológico e epidemiológico em um hospital universitário de Assunção - Parag̉uai
}

\author{
Infectious keratitis in children: an epidemiological and microbiological study in a \\ universitary hospital in Asunción - Paraguay
}

\author{
Eduardo Maidana ${ }^{1}$ \\ Richard González ${ }^{2}$ \\ Luiz Alberto Soares de Melo Júnior ${ }^{3}$ \\ Luciene Barbosa de Souza ${ }^{4}$
}

${ }^{1}$ Médico residente do Departamento de Oftalmologia do Hospital de Clínicas da Universidade Nacional de Assunção. Paraguai.

${ }^{2}$ Médico residente do Departamento de Oftalmologia do Hospital de Clínicas da Universidade Nacional de Assunção. Paraguai.

${ }^{3}$ Médico colaborador do setor de Glaucoma do Departamento de Oftalmologia da Universidade Federal de São Paulo (Instituto da Visão). São Paulo (SP).

${ }^{4}$ Doutora do Departamento de Oftalmologia da Universidade Federal de São Paulo (Instituto da Visão). São Paulo (SP)

Endereço para Correspondência: Eduardo Maidana Rua Napoleão de Barros, 1098/12 - São Paulo (SP) CEP 04024-003

E-mail: drmaidanasimon@hotmail.com

Recebido para publicação em 16.06.2005

Versão revisada recebida em 29.07.2005

Aprovação em 19.08.2005

Nota Editorial: Depois de concluída a análise do artigo sob sigilo editorial e com a anuência do Dr. José Américo Bonatti sobre a divulgação de seu nome como revisor, agradecemos sua participação neste processo.

\begin{tabular}{|l|}
\hline RESUMO \\
\hline Objetivo: O objetivo do presente estudo é determinar os aspectos micro- \\
biológicos da ceratite infecciosa em crianças (0-18 anos) atendidas no \\
Departamento de Oftalmologia do Hospital de Clínicas da Universidade \\
Nacional de Assunção - Paraguai, em período de 14 anos (1988-2002). \\
Métodos: Estudo retrospectivo por análise de prontuários de 146 crianças \\
cuja idade variou de 0 a 18 anos com úlceras de córnea de etiologia \\
infecciosa, atendidas no Departamento de Oftalmologia do Hospital de \\
Clínicas da Universidade Nacional de Assunção - Paraguai, no período \\
compreendido entre março de 1988 a agosto de 2002. Todas as crianças \\
foram submetidas a colheita de material da úlcera infecciosa e este foi \\
encaminhado para análise microbiológica. Resultados: As culturas foram \\
positivas em 113 pacientes (77\%) e destas 78 (70\%) foram de etiologia \\
bacteriana e 35 (30\%) foram de etiologia fúngica. Das bactérias isoladas, \\
as principais foram: 18 (23,1\%) estafilococos coagulase-negativo, 15 \\
(19,2\%) Staphylococcus aureus, 10 (12,8\%) Pseudomonas aeruginosa e \\
10 (12,8\%) Streptococcus pneumoniae. Foram isolados 35 fungos dos \\
quais os principais foram: 9 (25\%) Acremonium ssp, seguidos de 5 (14\%) \\
Fusarium ssp, 5 (14\%) Aspergillus fumigatus. Conclusões: A ceratite \\
infecciosa em crianças atendidas em um Hospital Universitário (referência \\
terciária) na cidade de Assunção - Paraguai é com maior freqüência \\
bacteriana, com predomínio de gram-positivos.
\end{tabular}

Descritores: Ceratite/epidemiologia; Ceratite/microbiologia; Doenças corneanas/microbiologia; Úlcera da córnea; Infecções oculares fúngicas; Paraguai/epidemiologia; Criança

\section{INTRODUÇÃO}

As úlceras infecciosas corneanas constituem uma causa importante de baixa de acuidade visual na população infantil dos países em desenvolvimento. $\mathrm{Na}$ África, $70 \%$ das crianças cegas apresentam opacidades corneanas ${ }^{(1)}$.

As infecções corneanas em crianças podem produzir alterações que variam de ceratite ponteada leve à ulceração corneana grave com opacidades permanentes e perfuração ocular ${ }^{(2-3)}$.

As úlceras bacterianas podem acompanhar-se de sintomas de dor, fotofobia e baixa de acuidade visual. Podem-se observar sinais de edema palpebral, hiperemia conjuntival, quemose, injeção ciliar, lacrimejamento e secreção purulenta. $\mathrm{O}$ epitélio corneano pode estar ulcerado, com infiltração estromal ou necrose tecidual. A córnea pode apresentar, com freqüência, 
edema ao redor do infiltrado. Também podem existir células na câmara anterior, placas inflamatórias endoteliais e hipópio ${ }^{(2-3)}$. As úlceras bacterianas estão freqüentemente associadas a fatores de risco que interferem com a integridade do epitélio corneano, como uso de lentes de contato, trauma, medicações oculares contaminadas, mecanismos de defesa alterados e alteração estrutural da superfície corneana ${ }^{(4)}$.

$\mathrm{Na}$ população infantil de países em desenvolvimento, o trauma e os mecanismos de defesa alterados são os principais fatores de risco para o desenvolvimento de úlcera bacteriana ${ }^{(5)}$.

A ceratite fúngica, menos comum que a bacteriana, pode ser indistinguível desta, mas podem existir alguns fatores de risco como história de traumatismo com material vegetal e uso crônico de corticosteróides tópico ${ }^{(2)}$. Em algumas infecções fúngicas, sobretudo nas causadas por fungos filamentosos, as margens do infiltrado são hifadas, com extensões irregulares ao estroma adjacente. A superfície pode estar sobrelevada e podem existir lesões satélite (focos de infiltração afastados da lesão principal) e infiltrados em anel ao redor do infiltrado principal. A evolução é freqüentemente lenta ${ }^{(2)}$.

É de extrema importância a identificação dos fatores etiológicos causadores da úlcera de córnea infecciosa e os organismos patogênicos envolvidos para o desenvolvimento de estratégias no que se refere ao diagnóstico, tratamento e prevenção das infecções corneanas.

\section{OBJETIVOS}

O objetivo do presente estudo é determinar os aspectos microbiológicos da ceratite infecciosa em crianças (0-18 anos) atendidas no Departamento de Oftalmologia do Hospital de Clínicas da Universidade Nacional de Assunção - Paraguai.

\section{MÉTODOS}

Estudo retrospectivo por análise de prontuários de 146 crianças cuja idade variou de 0 a 18 anos com diagnóstico clínico de úlceras de córnea de etiologia infecciosa, atendidas no Departamento de Oftalmologia do Hospital de Clínicas da Universidade Nacional de Assunção - Paraguai, no período compreendido entre março de 1988 a agosto de 2002; e aprovado pelo Comitê de ética e Pesquisa da respectiva universidade.

Todas as crianças foram submetidas à colheita de material da úlcera infecciosa e este foi encaminhado para análise microbiológica. A colheita foi realizada por oftalmologistas experientes com auxílio de blefarostato e espátula de Kimura sob anestesia tópica com cloridrato de proparacaína ou sob narcose nos casos onde houve falta de colaboração. O material corneano obtido foi utilizado para: 1) exame a fresco (KOH a $10 \%)$, 2) coloração de Gram, 3) meio de cultura para isolar fungos (Sabouraud + cloranfenicol a 1\%, biggy Ágar) a uma temperatura de incubação de $28^{\circ} \mathrm{C}$ durante 15 dias, 4) meio de cultura para isolar bactérias (Ágar Sangue, Ágar Chocolate a $10 \%$ em atmosfera de $\mathrm{CO}_{2}$ e meio de tioglicolato) a uma temperatura de $37^{\circ} \mathrm{C}$ durante 5 dias. A identificação dos fungos se realizou por microcultivo em Ágar Sabouraud + cloranfenicol a $1 \%$ e a identificação das bactérias pelos métodos microbiológicos convencionais ${ }^{(6)}$.

A determinação do antibiograma foi realizada pelo método de difusão de Kirby Bauer e a interpretação, de acordo com as normas estandartizadas pelo National Committee for Clinical Laboratory Standards (NCCLS).

\section{RESULTADOS}

Foram avaliadas 146 crianças distribuídas por número de casos/ano conforme gráfico 1 ao longo do período de 1988 a 2002. O maior número de casos foi observado no ano de 1993 15 casos (Gráfico 1).

Do total de 146 pacientes, $90(61,6 \%)$ foram do sexo masculino e $56(38,3 \%)$ foram do sexo feminino. A faixa etária mais acometida do sexo masculino foi de 6-10 anos e no sexo feminino de 1-5 anos (Tabela 1). Não houve associação estatisticamente significante entre faixa etária e sexo dos pacientes $(P=$ 0,10 , teste exato de Fisher).

Oitenta por cento dos pacientes foram examinados e tratados no primeiro mês do aparecimento dos sintomas conforme dados da tabela 2 .

Quarenta e cinco $(30,8 \%)$ crianças eram provenientes da área rural e história de trauma ocular foi observada em 64

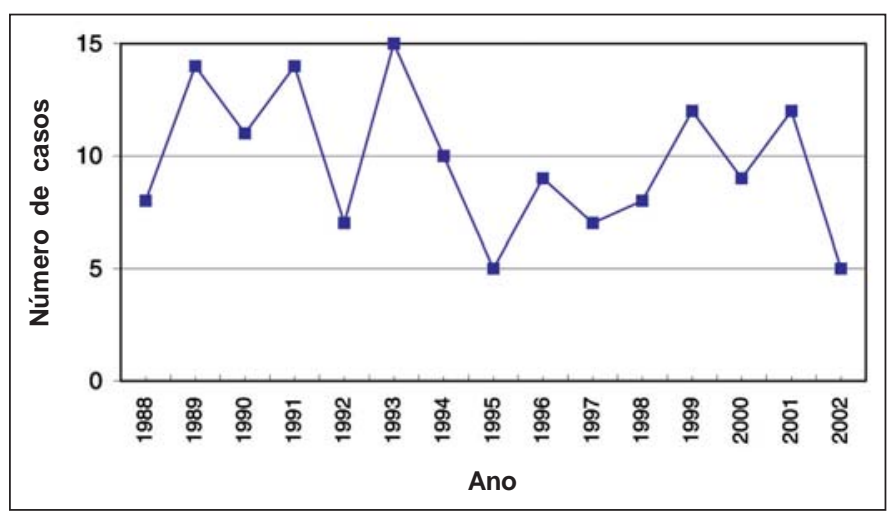

Gráfico1 - Distribuição do número de casos por ano

Tabela 1. Distribuição das crianças com ceratite infecciosa por grupo etário e sexo

\begin{tabular}{|lcc|}
$\begin{array}{l}\text { Idade } \\
\text { (anos) }\end{array}$ & $\begin{array}{c}\text { Sexo feminino } \\
\mathbf{n}(\%)\end{array}$ & $\begin{array}{c}\text { Sexo masculino } \\
\mathbf{n}(\%)\end{array}$ \\
$<1$ ano & $3(5,0)$ & $2(2,0)$ \\
$1-5$ & $21(36,0)$ & $24(26,0)$ \\
$6-10$ & $12(21,0)$ & $38(42,0)$ \\
$11-15$ & $17(30,0)$ & $22(24,0)$ \\
$16-18$ & $3(5,0)$ & $4(4,0)$ \\
Total & $56(38,3)$ & $90(61,6)$ \\
\hline
\end{tabular}


crianças $(43,8 \%)$, sendo o agente traumático principal materiais de origem vegetal (Tabela 3 ). Tratamento empírico prévio foi instituído em $98(67,1 \%)$ crianças antes da consulta com associação de antibiótico e corticóide tópicos (Tabela 3). As mães de 10 pacientes $(6,8 \%)$ referiam tratamento caseiro como uso de chás e mel de abelha no olho da criança.

As culturas foram positivas em 113 pacientes (77\%) e destas $78(70 \%)$ foram de etiologia bacteriana e $35(30 \%)$ foram de etiologia fúngica (Tabela 4). Das bactérias isoladas, as principais foram: $18(23,1 \%)$ estafilococos coagulase negativa, 15 (19,2\%) Staphylococcus aureus, 10 (12,8\%) Pseudomonas aeruginosa e 10 (12,8\%) Streptococcus pneumoniae (Tabela 5).

Foram isolados 35 fungos onde os principais foram os filamentosos e, entre os identificados foram obtidos 9 (25,7\%) Acre-

\begin{tabular}{|lc|}
\hline $\begin{array}{c}\text { Tabela 2. Tempo transcorrido do início dos sintomas até a primeira } \\
\text { consulta }\end{array}$ \\
Dias & Número de pacientes $(\%)$ \\
$0-7$ & $46(31,5)$ \\
$8-15$ & $46(31,5)$ \\
$16-23$ & $12(8,0)$ \\
$24-31$ & $12(8,0)$ \\
$>31$ & $30(20,5)$ \\
Total & $146(100,0)$ \\
\hline
\end{tabular}

\begin{tabular}{|lc|}
\hline \multicolumn{2}{|c|}{ Tabela 3. Características epidemiológicas dos pacientes com } \\
úlcera infecciosa
\end{tabular}

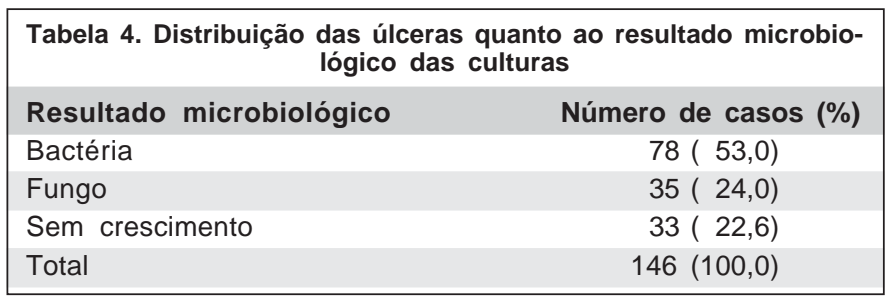

\begin{tabular}{|lc|}
\hline $\begin{array}{l}\text { Tabela 5. Distribuição das bactérias isoladas quanto ao gênero e } \\
\text { espécie }\end{array}$ \\
Bactéria & Número de casos (\%) \\
\hline Estafilococos coagulase negativa & $18(23,1)$ \\
Staphylococcus aureus & $15(19,2)$ \\
Streptococcus pneumoniae & $10(12,8)$ \\
Pseudomonas aeruginosa & $10(12,8)$ \\
Outras* & $25(32,1)$ \\
Total & $78(100,0)$ \\
*Streptococcus viridans, Klebsiella pneumoniae, Moraxella nonliquefasciens, \\
Proteusmirabilis, Escherichiacoli, Neisseriagonorrhoeaee Haemophilus species. \\
\hline
\end{tabular}

monium ssp, seguidos de 5 (14,3\%) Fusarium ssp, 5 (14,3\%) Aspergilus fumigatus dentre outros mostrados na tabela $6.31,4 \%$ foram fungos filamentosos não identificados.

O tratamento inicial utilizado no serviço de referência baseou-se na bacterioscopia. Nas úlceras bacterianas iniciou-se monoterapia com ciprofloxacina $0,3 \%$ ou gentamicina $0,3 \%$ ou tobramicina $0,3 \%$ tópicos variando de 1 gota a cada 30 min até 3 horas; e para as úlceras fúngicas fluconazol $2 \mathrm{mg} / \mathrm{ml}$ colírio e ketoconazol $400 \mathrm{mg} / \mathrm{dia}$ via oral. Em alguns casos, foram utilizados colírios fortificados de gentamicina e cefalotina conforme preconizado na literatura médica ${ }^{(7)}$.

\section{DISCUSSÃO}

O principal fator de risco associado às úlceras infecciosas em nosso estudo é o trauma coincidente com outros estudos da literatura $^{(8-13)}$. Quando não há história de trauma, principalmente em crianças menores de 3 anos deve-se investigar doença sistêmica ou estado de imunodepressão ${ }^{(8)}$. Em recém-nascidos, devese considerar ainda, os casos de trauma de parto ou a contaminação através do canal de parto nos nascimentos por via vaginal, associados à ceratite por etiologia gonocócica. No presente estudo não foram coletados dados referentes ao tipo de parto.

As culturas foram positivas em 113 pacientes (77\%); achado similar aos $86,3 \%, 75,8 \%$ e $70 \%$ encontrados em estudos da literatura $^{(8,12-13)}$. Aproximadamente $23 \%$ das culturas apresentaram-se sem crescimento. Este dado é coincidente com os achados da literatura ${ }^{(12)}$, que demonstraram $24,1 \%$ de culturas negativas, porém maior do que o descrito por outro estudo ${ }^{(8)}$ que demonstrou $13,7 \%$ de culturas negativas e menor do que os $30 \%$ relatados por outros autores ${ }^{(13)}$. Os achados de culturas negativas podem ser atribuídos ao uso de medicações tópicas iniciadas empiricamente e à etiologia viral das ceratites infecciosas, uma vez que há necessidade de meios de cultura específicos não avaliados no presente estudo ${ }^{(14)}$. É interessante ressaltar que os achados de culturas negativas também podem ser atribuídos às limitações técnicas que ainda existem para cultura de material ocular, desde a coleta do material até o crescimento.

Observamos que as ceratites infecciosas na população estudada foram predominantemente de etiologia bacteriana (Tabela 4) coincidentes com achados na literatura mundial ${ }^{(8-10,12-13)}$, sen-

\begin{tabular}{|c|c|}
\hline Fungos & Número de casos (\%) \\
\hline Acremonium & $9(25,7)$ \\
\hline Fusarium & $5(14,3)$ \\
\hline Aspergillus fumigatus & $5(14,3)$ \\
\hline Curvularia & $2(5,7)$ \\
\hline Fungo filamentoso não identificado & $11(31,4)$ \\
\hline Penicillium & $1(2,8)$ \\
\hline Aspergillus flavus & $2(5,7)$ \\
\hline Total & $35(100,0)$ \\
\hline
\end{tabular}


do o agente etiológico mais comumente isolado o Estafilococos coagulase negativa em $23,1 \%$ dos casos no presente estudo (Tabela 5).

Staphylococcus coagulase negativa foi o mais freqüente organismo causador de ceratite infecciosa bacteriana em alguns estudos ${ }^{(12-13)}$. Em contrapartida, outro estudo relata a Pseudomonas aeruginosa como agente etiológico bacteriano mais freqüente ${ }^{(8)}$.

Nas ceratites fúngicas observamos um predomínio dos fungos filamentosos conforme outros estudos na literatura mundial $^{(8,10-13,15)}$. Alguns autores ${ }^{(8)}$, encontraram o Fusarium como o mais freqüente organismo causador de ceratite micótica enquanto outros ${ }^{(13,15)}$, encontraram Aspergilus como o mais freqüente organismo causador de ceratite infecciosa em seus estudos. No presente estudo o agente etiológico micótico mais comum foi o Acremonium em 25,7\% dos casos (Tabela 6).

$\mathrm{O}$ Acremonium é um incomum agente causador de ceratite micótica ocorrendo principalmente após trauma ou associado às alterações dos mecanismos de defesa oculares, particularmente quando antibióticos ou esteróides tópicos foram inicia$\operatorname{dos}^{(16)}$. No presente estudo, 43,8\% dos casos apresentaram história prévia de trauma e $67,1 \%$ relataram tratamento empírico com antibióticos e corticosteróides tópicos. É possível que fatores regionais também estejam associados ao achado de Acremonium como principal agente fúngico isolado, uma vez que outro estudo realizado na mesma cidade também obteve resultados semelhantes ${ }^{(14)}$.

As soluções anestésicas tópicas utilizadas para colheita do material devem ser, de preferência, sem associação com preservantes. O colírio de proparacaína $0,5 \%$ foi o utilizado neste estudo e é o mais indicado por não interferir com as diferentes técnicas de citologia e por ser o menos bactericida.

A maioria dos medicamentos oftalmológicos no Paraguai é vendida sem prescrição médica, portanto não é surpreendente que os pacientes tenham iniciado tratamento empírico antes de sua avaliação oftalmológica. A combinação de antibiótico e corticóide tópico foi a mais utilizada. Também é interessante mencionar que 10 mães referiam tratamento caseiro como uso de chás e mel de abelha no olho da criança e a contaminação desses preparados podem ter sido responsáveis por agravar ainda mais o quadro.

$\mathrm{O}$ tratamento inicial utilizado baseou-se na bacterioscopia. Nas úlceras bacterianas iniciamos ciprofloxacina $0,3 \%$, gentamicina $0,3 \%$ ou tobramicina $0,3 \%$ tópicos de acordo com a manifestação clínica e a preferência pessoal do oftalmologista. Em alguns casos, foram utilizados colírios fortificados de cefalotina e gentamicina conforme preconizado na literatura médica ${ }^{(7)}$.

Quanto ao tratamento das úlceras fúngicas é de extrema importância ressaltar que não dispomos em nosso país de colírios de natamicina e anfotericina $\mathrm{B}^{7}$, portanto utilizamos colírios contendo fluconazol $2 \mathrm{mg} / \mathrm{ml}$ (endovenoso) preparados pelos médicos.

$\mathrm{O}$ atraso no diagnóstico e início do tratamento se deu ao fato de que a grande maioria desses pacientes eram provenien- tes de áreas rurais e tiveram dificuldades para chegar à capital do país devido à pobre condição econômica para o transporte.

É necessário um estudo prospectivo com padronização do tratamento com colírios fortificados para melhores resultados estatísticos.

Ceratite infecciosa na infância não é tão frequentemente encontrada quanto nos adultos, sendo um desafio seu diagnóstico e tratamento. A história clínica geralmente é pobre, pois as crianças não informam bem e os pais muitas vezes não sabem relatar o ocorrido. É importante lembrar a dificuldade do exame oftalmológico em crianças que pouco colaboram com o oftalmologista, dificultando a colheita do material das úlceras e a instilação adequada dos colírios.

Por ser um estudo retrospectivo, existem limitações no que se refere à determinação da incidência e prevalência das úlceras infecciosas em crianças. Também não foram abordados os aspectos clínicos das úlceras infecciosas e dados de acuidade visual pré-tratamento e pós-tratamento.

A úlcera corneana é uma afecção ocular séria que pode levar a uma importante perda da visão necessitando de uma adequada orientação e educação da população, como o desencorajamento para automedicação, leis que proíbam as vendas de medicamentos sem prescrição médica e a melhora das condições para uma rápida procura de assistência médica especializada.

\section{CONCLUSÕES}

Este estudo retrospectivo nos mostra que as úlceras infecciosas em crianças no Paraguai foram na maioria de etiologia bacteriana seguida por fungos, principalmente os filamentosos, resultados que são compatíveis com outros estudos previamente realizados.

\section{ABSTRACT}

Purpose: To describe the microbiologic aspects of infectious keratitis in children (0-18 years old) examined at the Department of Ophthalmology of the National University of Asunción - Paraguay, during a 14-year period (1988-2002). Methods: The authors retrospectively studied 146 children, under 18 years old, with infectious keratitis at the Department of Ophthalmology of the National University of Asunción - Paraguay, from 1988 to 2002. Results: The cultures were positive in 113 patients $(77 \%)$ with $70 \%$ of bacterial and $30 \%$ of fungal etiology. Coagulase-negative Staphylococcus (23.1\%), Staphylococcus aureus (19.2\%), Pseudomonas aeruginosa (12.8\%) and Streptococcus pneumoniae (12.8\%) were the most common microorganisms isolated. Acremonium ssp (25\%), Fusarium ssp (14\%) and Aspergillus fumigatus (14\%) were the fungi isolated. Conclusions: Ulcerative keratitis in children examined at the Department of Ophthalmology of the National University of Asunción - Paraguay is of bacterial origin in most of the cases. 
Keywords: Keratitis/epidemiology; Keratitis/microbiology; Corneal diseases/microbiology; Corneal ulcer; Eye infections, fungal; Paraguay/epidemiology; Child

\section{REFERÊNCIAS}

1. Gilbert CE, Wood M, Waddel K, Foster A. Causes of childhood blindness in east Africa: results in 491 pupils attending 17 schools for the blind in Malawi, Kenya and Uganda. Ophthalmic Epidemiol. 1995;2(2):77-84.

2. Grayson M. Abordaje diagnóstico a las enfermedade de la córnea. In: Grayson M. Enfermedades de la córnea. 4a ed. Madrid: Harcout Brace; 2000. p.192.

3. Kanski JJ. Oftalmología clínica: uma abordagem sistemática. $3^{\mathrm{a}}$ ed. Rio de Janeiro: Rio Med Livros; 2000. 83p.

4. American Academy of Ophthalmology. Clinical aspects of infectious diseases of the eyelids, conjunctiva, cornea, and sclera. In: American Academy of Ophthalmology. External disease and cornea. San Francisco, CA. The Foundation of the American Academy of Ophthalmology; 2001-2002. p.169.

5. Chirambo MC, Benezra D. Causes of blindness among student in blind school institutions in a developing country. Br J Ophthalmol. 1976;60(9):665-8.

6. Miño de Kaspar H, Zoulek G, Paredes ME, Alborno R, Medina D, Centurion de Morinigo M, et al. Mycotic keratitis in Paraguay. Mycoses. 34(5-6):251-4.

7. Krachmer JH, Mannis M, Holland EJ. Cornea. St Louis, Mosby; 1997. 1178p.
8. Cruz OA, Sabir SM, Capo H, Alfonso E. Microbial keratitis in childhood. Ophthalmology. 1993;100(2):192-6.

9. Grayson M. Enfermedades de la córnea. 4a ed. Madrid: Harcourt Brace; 2000. p.213.

10. American Academy of Ophthalmology. Clinical aspects of infectious diseases of the eyelids, conjunctiva, cornea, and sclera. In: American Academy of Ophthalmology. External disease and córnea. San Francisco, CA. The Foundation of the American Academy of Ophthalmology; 2001-2002. p.171-6.

11. Grayson M. Queratitis infecciosas: fúngica y parasitaria. In: Grayson M. Enfermedades de la córnea. $4^{\underline{a}}$ ed. Madrid: Harcout Brace; 2000. p.259.

12. Clinch TE, Palmon FE, Robinson MJ, Cohen EJ, Barron BA, Laibson PR. Microbial keratitis in children. Am J Ophthalmol. 1994:117(1):65-71.

13. Vajpayee RB, Ray M, Panda A, Sharma N, Taylor HR, Murthy GV, et al. Risk factors for pediatric presumed microbial keratitis: a case-control study. Cornea. 1999;18(5):565-9.

14. Laspina F, Samudio M, Cibils D, Ta CN, Fariña N, Sanabria R, et al. Epidemiological characteristics of microbiological results on patients with infectious corneal ulcers: a 13-year survey in Paraguay. Graefe's Arch Clin Exp Ophthalmol. 2004;242(2):204-9.

15. Panda A, Sharma N, Das G, Kumar N, Satpathy G. Mycotic keratitis in children: epidemiologic and microbiologic evaluation. Cornea. 1997;16(3):295-9.

16. Fincher RE, Fisher JF, Lovell RD, Newman CL, Espinel-Ingroff A, Shadomy J. Infection due to the fungus Acremonium (Cephalosporium). Medicine. 1991; 70(6):398-409. 